Research Article

\title{
Determining the Thermal Conductivity of Clay during the Freezing Process by Artificial Neural Network
}

\author{
Xiuling Ren $\mathbb{D}^{1,2}$, Yanhui You $\mathbb{D}^{1},{ }^{1}$ Qihao Yu $\mathbb{D},{ }^{1}$ Guike Zhang $\left(\mathbb{D},{ }^{3}\right.$ Pan Yue $\mathbb{D},^{3}$ \\ and Mingyang Jin $\mathbb{D}^{1,2}$ \\ ${ }^{1}$ State Key Laboratory of Frozen Soil Engineering, Northwest Institute of Eco-Environment and Resources, \\ Chinese Academy of Sciences, Lanzhou 730000, Gansu, China \\ ${ }^{2}$ University of Chinese Academy of Sciences, Beijing 100049, China \\ ${ }^{3}$ Yalong River Hydropower Development Company, Ltd, Chengdu 610065, Sichuan, China
}

Correspondence should be addressed to Qihao Yu; yuqh@lzb.ac.cn

Received 27 January 2021; Revised 2 March 2021; Accepted 13 March 2021; Published 27 March 2021

Academic Editor: Xiangtian Xu

Copyright (C) 2021 Xiuling Ren et al. This is an open access article distributed under the Creative Commons Attribution License, which permits unrestricted use, distribution, and reproduction in any medium, provided the original work is properly cited.

\begin{abstract}
Thermal conductivity is an important thermal parameter in engineering design in cold regions. By measuring the thermal conductivity of clay using a transient hot-wire method in the laboratory, the influential factors of the thermal conductivity of soils during the freezing process were analyzed, and a predictive model of thermal conductivity was developed with an artificial neural network (ANN) technology. The results show that the variation of thermal conductivity can be divided into three stages with decreasing temperature, positive temperature stage, transition stage, and negative temperature stage. The thermal conductivity increases sharply in the transition stage. The difference between the thermal conductivity at positive and negative temperature is small when the dry density of the soil specimens is larger than the critical dry density, while the difference is large if the dry density is less than the critical dry density. As the negative temperature decreases, the larger the moisture content of the soil specimens, the larger the increase of thermal conductivity. The effect of initial moisture content on thermal conductivity is more significant than that of dry density and temperature. The change tendency of the thermal conductivity calculated by the established ANN model is basically consistent with that of the laboratory-measured values, indicating that this model can be able to accurately predict the thermal conductivity of the soil specimens in the freezing process.
\end{abstract}

\section{Introduction}

The thermal conductivity of soils is an important thermal parameter for modeling the freeze-thaw process of soils and determining the frozen and thawed depth of soils [1]. And the thermal conductivity represents the heat conduction of soils, which will affect the heat transfer process of soils. As we need economic development, more major projects will be built in cold regions, and their thermal stability is crucial for the operation. Therefore, it is very important to study the variation and predictive models of the thermal conductivity of soils during a freezing process.

The thermal conductivity of soils is mainly affected by mineral types, moisture content, dry density, temperature, and grain size [2-11]. A large number of studies have analyzed the variation of the thermal conductivity of soils under the influence of various factors and established the empirical relationship between the thermal conductivity and the impacting factors. The thermal conductivity of soils increases with increasing moisture content $[2,3,7,8]$. However, the increase of the thermal conductivity of soils in the frozen and thawed status is different, which is mainly caused by the phase transition of water in the frozen state [12]. For a special soil, a power function relationship can be established between the thermal conductivity and the moisture content of soils [13]. The thermal conductivity of soils increases with increasing dry density $[2,7,14]$. The influence of moisture content on thermal conductivity is more significant than that of dry density [15]. The thermal conductivity of soils increases with decreasing temperature $[4,8]$. The thermal conductivity of soils in the frozen state is larger than that in the thawed state [4], and the variation of the 
thermal conductivity with temperature is related to moisture content [4]. Some studies indicated that the porosity and degree of saturation affect the thermal conductivity of sandy soils $[16,17]$, and the thermal conductivity of sand increases with decreasing porosity and increasing degree of saturation [17]. In addition, soil particle size, structure, and bulk density also affect the thermal conductivity of soils $[2,8,18]$. The thermal conductivity of coarse-grained soils is larger than that of fine-grained soils $[2,8,18]$.

Many types of predictive models of thermal conductivity have been proposed, mainly divided into theoretical, empirical, and other models [19]. In terms of theoretical models, Wiener [20] established the series and parallel models of the thermal conductivity based on the heat flow direction and the arrangement of three-phases of porous media. According to Maxwell's equation, Devries [21] assumed that the solid particles of soils were uniformly distributed in the continuous pore fluid and proposed a theoretical model of the thermal conductivity of soils. Johansen [22] proposed a weighted geometric average model to calculate the thermal conductivity of soils. In terms of empirical models, Kersten [4] used a single thermal probe method to test the thermal conductivity of 19 different types of soils by considering the effect of moisture content and dry bulk density and established the empirical equations of the thermal conductivity for silt and clay soils and sandy soils in the frozen and unfrozen state, respectively. Johansen [22] firstly proposed the concept of the normalized thermal conductivity $\left(\lambda_{r}\right)$, namely, "Kersten's number, Ke," expressed the moisture content and dry density in the Kersten [4] model by a degree of saturation, and normalized the moisture content and dry density. Cote and Konrad [23] proposed a new normalized thermal conductivity model based on the research of Johansen [22]. Chen [17] established the empirical equation of the thermal conductivity based on the porosity and degree of saturation and compared the calculated results with the experimental results and the results in the published literature. And $\mathrm{Bi}$ et al. [24] proposed a generalized model for the thermal conductivity of the freezing soils based on frost heave and components of soils.

Artificial neural networks (ANNs) are also widely used in the prediction of thermal parameters $[9,25]$. Some researchers used the ANN models to calculate the thermal conductivity [9, 26-28] and thermal diffusivity [29] of soils. He and Huang [26] used the BP neural network model to determine the thermal conductivity of soils by analyzing the relationship between the thermal conductivity and the physical property index of soils and pointed out that the predicted thermal conductivity is close to the measured thermal conductivity values. Based on the ANN technology, Zhang et al. [27] calculated the layered thermal conductivity of the undisturbed soils in the field by taking moisture content and porosity as input layer neurons and the thermal conductivity as the output layer neuron. Zhang et al. [9] established an individual model of the thermal conductivity for different types of soils and a generalized model by considering the influence of soil types via ANN technology, compared the predicted thermal conductivity with the calculated results of three empirical models, and pointed out that the predicted results of the two ANN models are close to the measured thermal conductivity values.
In the published research studies, when calculating the thermal conductivity of soils considering the frozen and thawed status of soils, the influence of the variation of the temperature of the soil in the freezing process on the thermal conductivity model is considered in few studies. Although the ANN models have been successfully used to predict the thermal conductivity of soils, the applicable condition of each predictive model is different, the influence of the variation of negative temperature on the thermal conductivity is less considered in the predictive models, and the ANN technology is seldom used to establish the predictive models of the thermal conductivity of soils during a freezing process. Therefore, the objective of this study is to understand the variation of the thermal conductivity of clay under various impacting factors during a freezing process where the temperature changes from positive to negative and to develop a predictive model of the thermal conductivity of soil during the freezing process by ANN technology. The thermal conductivity of clay is measured in the laboratory, and the effects of initial moisture content, initial dry density, and temperature on the thermal conductivity of soils are analyzed. Based on this, considering the influence of initial moisture content, initial dry density, and temperature on thermal conductivity, a predictive model of the thermal conductivity of soils is developed via ANN technology, which can completely calculate the thermal conductivity of soils when the temperature changes from a positive value to a negative value. And it is validated by comparing the predicted thermal conductivity results with the measured thermal conductivity results.

\section{Experimental Materials and Methods}

2.1. Experimental Materials. In this study, the clay used for the test was obtained from the Lianghekou region, Sichuan province, China. Figure 1 shows the grain size distribution curve of clay. Figure 2 shows the compaction curve of clay. The maximum dry density is $1.78 \mathrm{~g} / \mathrm{cm}^{3}$. The optimum water content by weight is $17.0 \%$. The basic physical parameters for the soil specimens are listed in Table 1 .

In order to study the variation of the thermal conductivity of soils in the compacted and loose status, the thermal conductivity of soils over a wide range of dry densities of about $1.00 \sim 1.92 \mathrm{~g} / \mathrm{cm}^{3}$ was tested. The interval within the large dry density was small, and the interval within the low dry density was large; the main purpose is to highlight and analyze the variation of the thermal conductivity of the compacted soils. The temperature decreased step by step from $5^{\circ} \mathrm{C}$ to $-10^{\circ} \mathrm{C}$ in a freezing process. The soil specimens were divided into 4 groups according to the initial moisture content of different soil specimens, and a total of 192 soil specimens were measured. The specific experimental conditions are shown in Table 2.

\subsection{Experimental Methods}

2.2.1. Specimen Preparation Process. Firstly, soils were airdried and crushed, sieved over $2 \mathrm{~mm}$, and the air-dry moisture content of soils was measured by the drying 


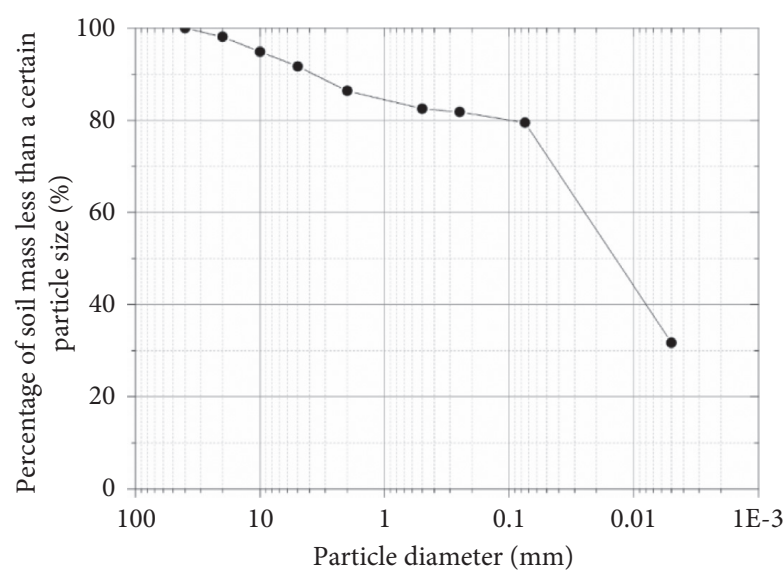

Figure 1: Grain size distribution curve of clay.

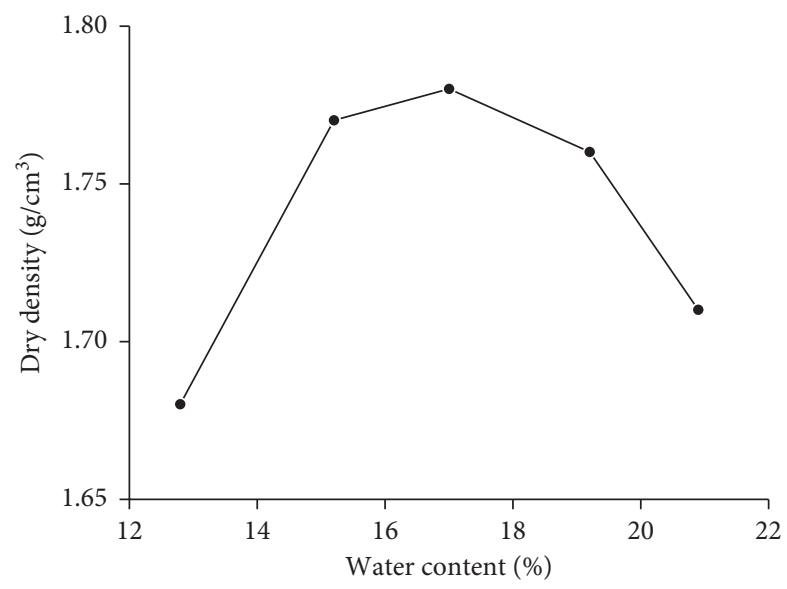

Figure 2: Compaction curve of clay.

TABLE 1: Basic physical parameters for the soil specimens.

\begin{tabular}{lcccc}
\hline $\begin{array}{l}\text { Optimum water content } \omega_{o p} \\
(\%)\end{array}$ & $\begin{array}{c}\text { Maximum dry density } \rho_{d \max } \\
(\%)\end{array}$ & $\begin{array}{c}\text { Liquid limit } W_{L} \\
(\%)\end{array}$ & $\begin{array}{c}\text { Plastic limit } W_{P} \\
(\%)\end{array}$ & $\begin{array}{c}\text { Soil specific gravity } G_{s} \\
\left(\mathrm{~g} / \mathrm{cm}^{3}\right)\end{array}$ \\
\hline 17.0 & 1.78 & 36.9 & 19.8 & 2.72 \\
\hline
\end{tabular}

Table 2: Experimental conditions.

\begin{tabular}{lccc}
\hline Impacting factors & Initial moisture content $(\%)$ & Initial dry density $\left(\mathrm{g} / \mathrm{cm}^{3}\right)$ & Temperature $\left({ }^{\circ} \mathrm{C}\right)$ \\
\hline & 14 & $1.92,1.88,1.82,1.73,1.63,1.58,1.44,1.15$ & $5,1,-0.5,-1,-5,-10$ \\
Experimental conditions & 16 & $1.9,1.86,1.81,1.71,1.62,1.52,1.43,1.14$ & $5,1,-0.5,-1,-5,-10$ \\
& 18 & $1.72,1.68,1.62,1.54,1.45,1.36,1.27,1.09$ & $5,1,-0.5,-1,-5,-10$ \\
& 20 & $1.69,1.65,1.6,1.51,1.42,1.33,1.24,1$ & $5,1,-0.5,-1,-5,-10$ \\
\hline
\end{tabular}

method. Secondly, according to the experimental conditions, different amounts of distilled deionized water were added to prepare soil samples with different initial moisture content. Soil samples were stored in a sealed bag for $24 \mathrm{~h}$ to make the moisture in the soil samples uniformly distributed. Then, the soils were compacted layer by layer in a cylindrical mold. In order to ensure that the dry density of the upper and lower parts of the soil specimens was basically the same, the soil specimens were compacted from the upper and lower ends.
The dry density of the soil specimens was controlled by controlling the height and quality of each layer of the soil specimens. In this way, cylinder soil specimens with different initial moisture content and dry density (Table 2) were obtained with a diameter of $61.8 \mathrm{~mm}$ and a height of $50 \mathrm{~mm}$. Finally, the soil specimens were quickly covered with plastic film to keep the moisture content unchanged and were stored for $24 \mathrm{~h}$, so as to ensure that the moisture was uniformly distributed in the soil specimens. 
2.2.2. Test Process of Thermal Conductivity. In this study, the thermal conductivity of the soil specimens was measured by a Thermal Properties Analyzer (Anter Quickline-30) (Figure 3), the measuring range is $0.3 \sim 2.0 \mathrm{~W} /(\mathrm{m} \cdot \mathrm{K})$, and the instrument accuracy is $\pm 0.0001 \mathrm{~W} /(\mathrm{m} \cdot \mathrm{K})$. The Thermal Properties Analyzer is mainly based on the transient hotwire method to determine the thermal conductivity of the soil specimens. Firstly, the temperature of the thermostat (the accuracy is $\pm 0.01^{\circ} \mathrm{C}$ ) was set to $5^{\circ} \mathrm{C}$; when the real-time temperature in the thermostat was the same as the preset temperature, the soil specimens and the instrument probe were placed into the thermostat together. After about $24 \mathrm{~h}$, both the temperature inside the soil specimens and that of the probe were constant at $5^{\circ} \mathrm{C}$. Secondly, the probe was placed on the top surface of the soil specimen; after the temperature of the Thermal Properties Analyzer stabilized, the thermal conductivity of the upper end of the soil specimen was measured. Then, the lower end of the soil specimen was put upwards, and the probe was placed to measure the thermal conductivity. The average of the two measured results was taken as the thermal conductivity of the soil specimen. Finally, according to the designed experimental temperature, the temperature of the thermostat was adjusted step by step in a freezing process, and the thermal conductivity of the soil specimens was measured at each temperature in a freezing process in accordance with the previous steps. At each temperature, in order to make the temperature of the soil specimens reach stabilization, the soil specimens were stored in the thermostat for about $6 \mathrm{~h}$ before the thermal conductivity was measured. And in the transition process where the temperature changes from positive to negative, the stored time of the soil specimens is about $12 \mathrm{~h}$.

\section{Experimental Results and Discussion}

The impacting factors of the thermal conductivity of soils mainly include mineral component, moisture content, dry density, temperature, and freeze-thaw cycles $[6,8,12,22,27]$. The variation of the thermal conductivity of the soil specimens under the effect of initial moisture content, initial dry density, and temperature will be mainly analyzed in this section. Based on this, the ANN technology is used to develop a predictive model for calculating the thermal conductivity of the soil specimens under the same experimental conditions.

\subsection{Variation of the Thermal Conductivity of the Soil Specimens}

3.1.1. Influence of Initial Dry Density and Moisture Content on Thermal Conductivity. The variation of the thermal conductivity of the soil specimens with dry density is shown in Figure 4. Under the same initial moisture content of the soil specimens and temperature, the thermal conductivity of the soil specimens increases with increasing dry density, and there is basically a linear change between the two (Figure 4). The main reasons for the increase of the thermal conductivity of the soil specimens with increasing dry density are that, on the one hand, the increase in dry density will increase the content of solid particles inside the soil specimens and the connectivity between soil skeletons and then will increase the heat conduction of the soil specimens. On the other hand, both the pores and porosity of the soil specimens decrease, and the thermal conductivity of the soil skeleton is far larger than that of air (Table 3); then, the thermal conductivity of the soil specimens increases. For a given moisture content, the increase of the thermal conductivity of the soil specimens with dry density is independent of temperature.

In addition, the moisture content of soils is one of the impacting factors of the thermal conductivity of soils. It can be seen from Figure 4 that at the temperature of $5^{\circ} \mathrm{C}$ and $-10^{\circ} \mathrm{C}$, the thermal conductivity with the moisture content of $14 \%$ at the dry density of $1.44 \mathrm{~g} / \mathrm{cm}^{3}$ is $0.55 \mathrm{~W} /(\mathrm{m} \cdot \mathrm{K})$ and $0.87 \mathrm{~W} /(\mathrm{m} \cdot \mathrm{K})$, respectively; and the thermal conductivity with the moisture content of $20 \%$ at the dry density of $1.42 \mathrm{~g} /$ $\mathrm{cm}^{3}$ is $1.19 \mathrm{~W} /(\mathrm{m} \cdot \mathrm{K})$ and $1.48 \mathrm{~W} /(\mathrm{m} \cdot \mathrm{K})$, respectively. It indicates that the dry density of the soil specimens with the moisture content of $20 \%$ and $14 \%$ is basically the same, while the thermal conductivity with the moisture content of $20 \%$ is larger than that with the moisture content of $14 \%$ at positive and negative temperatures. The main reasons for this phenomenon are that, on the one hand, as the moisture content of the soil specimens increases, the pores in the soil specimens will be filled with water, the air in the pores will be expelled, the porosity of the soil specimens will decrease, and the thermal conductivity of water is far larger than that of air. On the other hand, the increase in the moisture content will reduce the space between soil particles and will increase the thermal conduction of soil particles.

\subsubsection{Influence of Temperature on Thermal Conductivity.} The influence of temperature on the variation of the thermal conductivity of the soil specimens is shown in Figure 5. The results showed that, under the same initial moisture content and dry density, the variation of the thermal conductivity of the soil specimens with temperature can be roughly divided into three stages. In Stage I, positive temperature stage $\left(5 \sim 1^{\circ} \mathrm{C}\right)$, the thermal conductivity of the soil specimens decreases slightly with decreasing temperature. The main reason for this phenomenon is that, in this stage, the movement of water molecules inside the soil specimens is intense with increasing temperature, which will increase the heat exchange capacity inside the soil specimens. In Stage II, the transition stage from positive to negative temperature $\left(1 \sim-1^{\circ} \mathrm{C}\right)$, the thermal conductivity of the soil specimens sharply increases with decreasing temperature. The main reasons for this phenomenon are that, firstly, when the temperature is up to the freezing point within this change range of temperature, the water in the soil specimens will transform into ice, the solid phase of the threephases system will change from soil skeleton to soil skeleton and ice, the volume of the soil specimens will increase, and the content of unfrozen water, air, and the pores in the soil specimens will decrease. Secondly, the thermal conductivity of ice is about 4 times that of water and far larger than that of air (Table 3). In Stage III, negative temperature stage $\left(-1 \sim-10^{\circ} \mathrm{C}\right)$, 


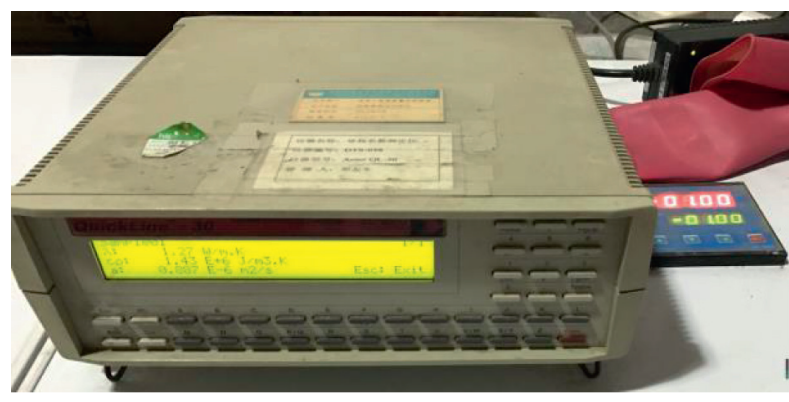

(a)

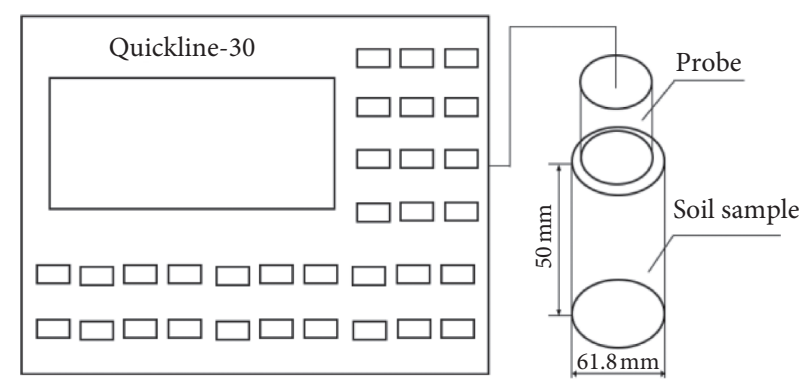

(b)

Figure 3: Experiment apparatus for thermal conductivity. (a) Photograph. (b) Schematic diagram.

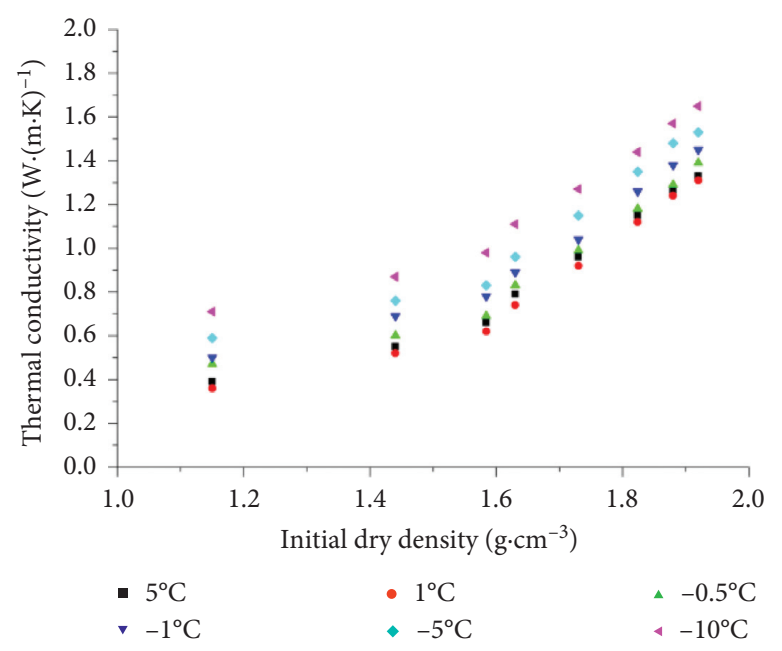

(a)

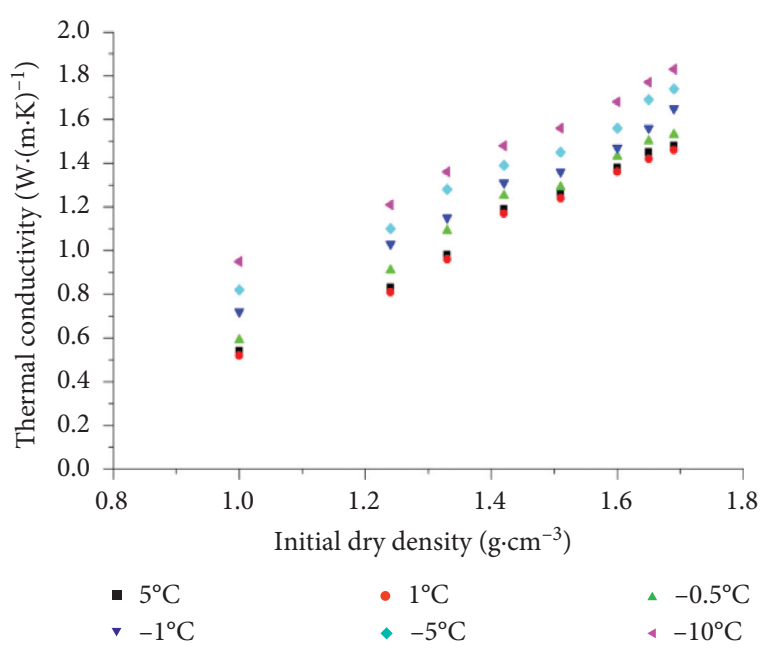

(b)

Figure 4: Variation of the thermal conductivity of the soil specimens with dry density. (a) $w=14 \%$. (b) $w=20 \%$.

TABLE 3: Thermal conductivity of basic constituents of soils [12].

\begin{tabular}{lcccc}
\hline Basic constituents & Water & Ice & Air & Soil skeleton \\
\hline $\begin{array}{l}\text { Thermal } \\
\text { conductivity/(W/ }(\mathrm{m} \cdot \mathrm{K}))\end{array}$ & 0.465 & 2.21 & 0.024 & $1.2 \sim 7.5$ \\
\hline
\end{tabular}

as the negative temperature continues to decrease, the thermal conductivity of the soil specimens continues to increase, but the increase is small. This is because although the negative temperature decreases, the limited water in the soil specimens limits the increase of ice.

It can be found from Figure 5 that, for given initial moisture content, the difference between the thermal conductivity of the soil specimens at positive and negative temperatures is related to the dry density. There is a critical dry density; when the dry density is larger than the critical dry density, the difference between the thermal conductivity of the soil specimens at positive and negative temperatures is small, indicating that the thermal conductivity is less affected by temperature. However, when the dry density is less than the critical dry density, the difference between the thermal conductivity of the soil specimens at positive and negative temperatures is large, indicating that the thermal conductivity is greatly affected by temperature. The main reason for the above phenomenon is that the soil specimens with low dry density are loose and with many pores in them; after the water in the soil specimens transforms into ice under the negative temperature condition, the reduction of pores in the soil specimens is more obvious, and the thermal conductivity of ice is much greater than that of air (Table 3).

According to the calculation, the average increment of the thermal conductivity of the soil specimens between the initial moisture content of $20 \%$ and $14 \%$ is $0.05 \mathrm{~W} /(\mathrm{m} \cdot \mathrm{K})$; that of the soil specimens between the maximum and minimum initial dry density is $0.024 \mathrm{~W} /(\mathrm{m} \cdot \mathrm{K})$; that of the soil specimens between the temperature of $5^{\circ} \mathrm{C}$ and $-10^{\circ} \mathrm{C}$ is $0.021 \mathrm{~W} /(\mathrm{m} \cdot \mathrm{K})$. It can be seen that, under the influence of different impacting factors, the increase of the thermal conductivity of the soil specimens from large to small is as follows: initial moisture content, initial dry density, and temperature. It indicates that the initial moisture content has the greatest effect on the thermal conductivity, followed by the initial dry density and temperature.

3.2. Development of the ANN Model. In this paper, based on the experimental results, a predictive model of the thermal conductivity of the soil specimens is developed via the ANN technology, and the calculated results are compared with the 


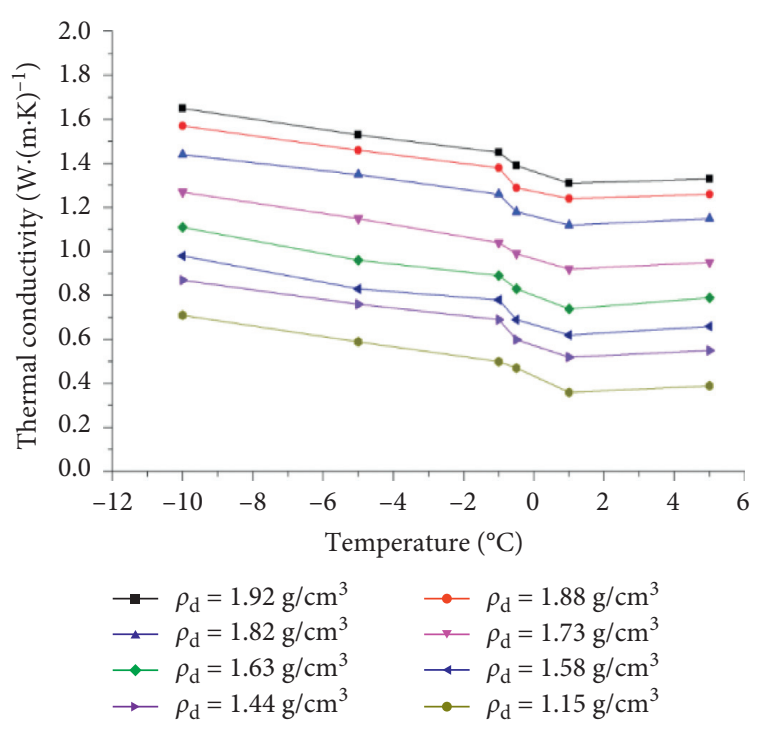

(a)

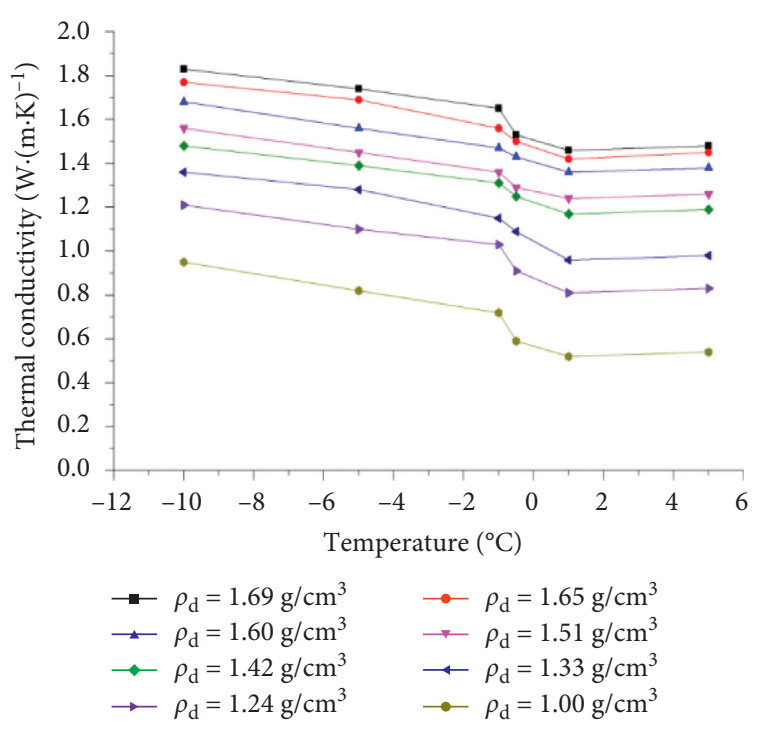

(b)

FIgURE 5: Variation of the thermal conductivity of the soil specimens with temperature. (a) $w=14 \%$. (b) $w=20 \%$.

laboratory-measured results to validate the correctness of the calculated results of the model.

\subsubsection{Establishment of the ANN Model. ANN is a multilayer} feed-forward neural network, which is composed of an input layer, hidden layer, and output layer, and each layer is composed of different numbers of neurons. In this calculation process, there are 3 neurons in the input layer, including initial moisture content, initial dry density, and temperature of the soil specimens. And there is only one neuron in the output layer, which is the predicted thermal conductivity of the soil specimens. Figure 6 shows the schematic diagram of the structure of the ANN model to calculate the thermal conductivity of the soil specimens. And $x, h l$, and $y$ denote the neuron of the input layer, hidden layer, and output layer, respectively. Each neuron in the input layer is connected with each neuron in the hidden layer by weights, and each neuron in the hidden layer is connected with the neuron in the output layer by weights.

The ANN uses the Backpropagation algorithm, and the learning process is mainly divided into two stages. The first stage is to input the known learning soil specimens and to calculate the output of each neuron backward from the input layer of the network by setting the structure of the network and the weights and thresholds of the previous iteration; then, the output of each neuron is calculated backward from the input layer of the network. The second stage is to modify the weights and thresholds, to calculate the effect of each weight and threshold on the total error from the output layer, and then to modify each weight and threshold. The two stages are repeated alternately until the convergence is reached.

In addition, the training and test process of multilayer perceptrons (MLPs) are carried out in the ANN toolbox of Matlab 2019. The software is widely used in algorithm development, data analysis, data visualization, and numerical calculation [30].

3.2.2. Parameters Setting. In the general calculation process of the ANN model, the data set is mainly divided into two subsets: the training and validation set. However, it was found that dividing the data set in this way will lead to the model overfitting [31]. And overfitting will prevent the MLPs from properly generalizing the new data in the memory training patterns [32]. Therefore, the data set is divided into three subsets in this calculation process, which are used for training, validation, and testing, respectively, and accounting for $58 \%, 17 \%$, and $25 \%$ of all data. The training data is mainly used to update the weights of the ANN and to establish the most suitable structure of the neural network [25]. The validation data is used to verify the validity of the established model. The testing data is used to determine the thermal conductivity of soils and to validate the accuracy of the model.

The calculated requirements can be met when a network is with one hidden layer [33]; hence, one hidden layer is used in this paper. In addition, the number of neurons in the hidden layer directly affects the performance of the ANN model [27]. Therefore, the number of neurons in the hidden layer is very important for choosing the appropriate structure of the ANN model. The empirical calculation equation for the number of neurons in the hidden layer is [30]

$$
n=\sqrt{n_{i}+n_{0}}+a
$$

where $n$ is the number of neurons in the hidden layer, $n_{i}$ is the number of neurons in the input layer, $n_{0}$ is the number of neurons in the output layer, and $a$ is a constant in the range of $1 \sim 10$. Then, the range of $n$ in this calculation is $3 \sim 12$. 


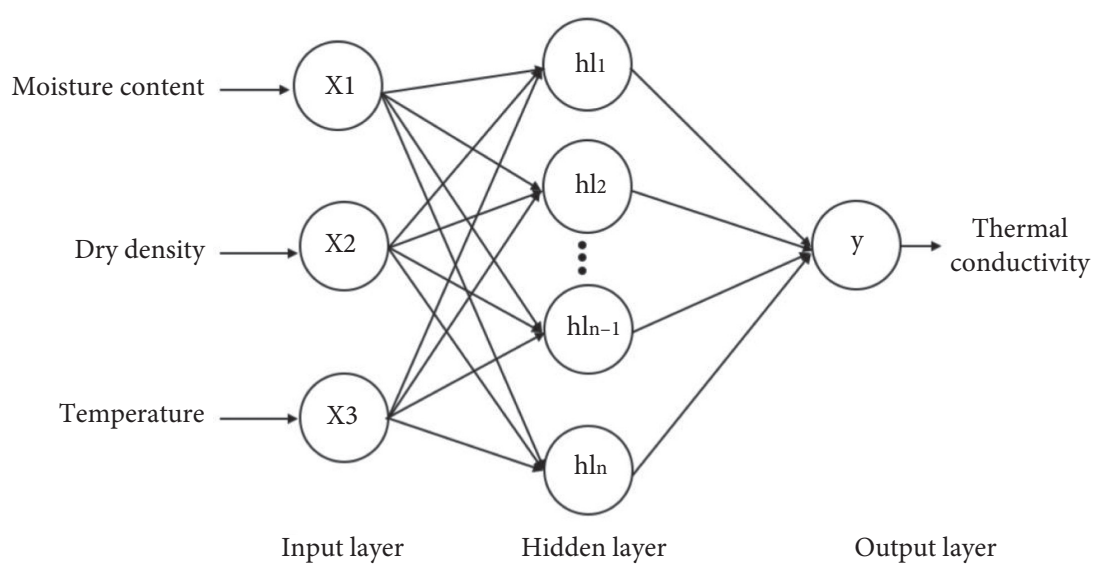

FIgURE 6: Schematic diagram of the structure of ANN model.

The optimum number of neurons in the hidden layer can be obtained by the following steps: firstly, selecting the number of neurons in the hidden layer to be 3 to train the model, and then, sequentially adding one neuron in the hidden layer for training. When the errors of training, validation, and testing results begin to increase, the training process is terminated. The number of neurons in the hidden layer is considered most appropriate when the errors of training, validation, and testing are small.

We adopt the sigmoid differentiable function as the transfer function of the hidden and output layer of the ANN. Then, the input and output data should be normalized to the range of $0 \sim 1$, and the calculation equation is

$$
x_{n}=\frac{x_{\max }-x}{x_{\max }-x_{\min }},
$$

where $x_{n}$ is the normalized data, $x_{\max }$ and $x_{\min }$ are the actual maximum and minimum value, respectively, and $x$ is the actual input and output data.

Table 4 shows the boundary values of the input and output data.

The Levenberg-Marquardt method was used for training the network. The maximum number of network iteration epochs and the expected error goal were selected as 1000 times and 0.0000001 , respectively. The learning rate (lr) was selected as 0.01 so as to obtain the most suitable structure of the ANN model.

3.2.3. Model Verification. The comparison between the predicted thermal conductivity of the soil specimens during the training, validation, and testing process of the model with the laboratory-measured thermal conductivity values is shown in Figure 7 . The predicted thermal conductivity values during training, validation, and testing are relatively close to the measured thermal conductivity values (Figure 7), indicating that the structure of the established ANN model is reasonable.

In addition, in this study, the correlation coefficient $\left(R^{2}\right)$, square root error (RMSE), mean absolute error (MAE), and variance $(V A F)$ are selected to further validate the accuracy of the calculated results of the established ANN model. The calculation equations are as follows:

$$
\begin{gathered}
\text { RMSE }=\sqrt{\frac{1}{n} \sum_{i=1}^{n}\left(y_{i}-y_{i}^{\prime}\right)^{2},} \\
V A F=\left[1-\frac{\operatorname{var}\left(y-y^{\prime}\right)}{\operatorname{var}(y)}\right] \times 100 \%,
\end{gathered}
$$

where $n$ is the number of the soil specimens, $y_{i}$ is the laboratory-measured thermal conductivity, $y_{i}^{\prime}$ is the thermal conductivity calculated by the model, and var is an abbreviation of variance. If the values of $R^{2}$ and $V A F$ are close to $1, R M S E$ and $M A E$ are close to 0 ; it means that the predicted thermal conductivity values of the model are close to the measured thermal conductivity values, and the predicted result is more accurate.

3.2.4. Performance Assessment of the Established Model. The comparison of the thermal conductivity of the soil specimens with the initial moisture content of $16 \%$ calculated by the ANN model with the laboratory-measured thermal conductivity is shown in Figure 8. The subscripts $m$ and $p$ of $\rho_{d m}$ and $\rho_{d p}$ denote the measured and predicted values, respectively. Under the same initial moisture content and dry density, the change tendency of the predicted results by the model is basically consistent with that of the measured results with temperature, and the two are relatively close, but the predicted values of the model are slightly larger than the measured values (Figure 8(a)). The correlation coefficient $\left(R^{2}\right)$ between the predicted values of the model and the measured values is high, which is 0.9869 (Figure $8(\mathrm{~b})$ ). Table 5 shows the values of $R^{2}, R M S E, M A E$, and VAF of the predicted results of the model compared with the measured results. The values of $R^{2}$ and $V A F$ are greater than 0.95 and $95 \%$, respectively (Table 5). It indicates that the established ANN model can accurately predict the thermal conductivity of the soil specimens.

The proposed model can be applied to calculate the thermal conductivity of clay in the frozen and unfrozen states and further used to calculate and analyze the variation of the temperature field of soils in cold regions and to estimate the frozen depth of soil. 
TABLE 4: Boundary values of the input and output data.

\begin{tabular}{lccc}
\hline Data & Variable & Maximum value & Minimum value \\
\hline \multirow{3}{*}{ Input data } & Moisture content $(\%)$ & 20 & 14 \\
& Dry density $\left(\mathrm{g} / \mathrm{cm}^{3}\right)$ & 1.92 & 1 \\
Output data & Temperature $\left({ }^{\circ} \mathrm{C}\right)$ & 5 & -10 \\
\hline
\end{tabular}

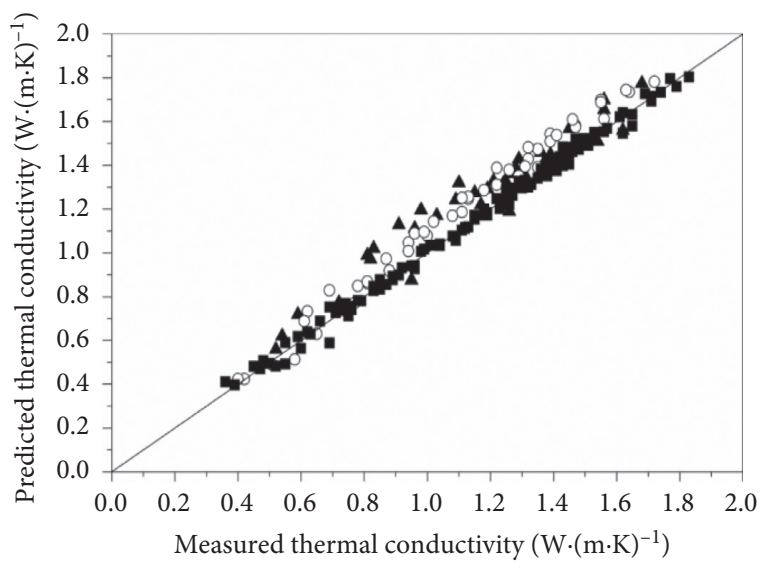

- Training data

- Testing data

- Validation data

FIGURE 7: Comparison of the predicted thermal conductivity values of the soil specimens by ANN with the measured thermal conductivity values.

TABLE 5: Comparison of the parameter values of the predicted thermal conductivity results of the model with the measured thermal conductivity results.

\begin{tabular}{lcccc}
\hline Data sets & $R^{2}$ & $R M S E(\mathrm{~W} /(\mathrm{m} \cdot \mathrm{K}))$ & $M A E(\mathrm{~W} /(\mathrm{m} \cdot \mathrm{K}))$ & 0.04 \\
\hline Training & 0.9974 & 0.02 & 0.1 & 99 \\
Testing & 0.9869 & 0.09 & 0.1 & 98 \\
Validation & 0.9561 & 0.11 & 95 \\
\hline
\end{tabular}
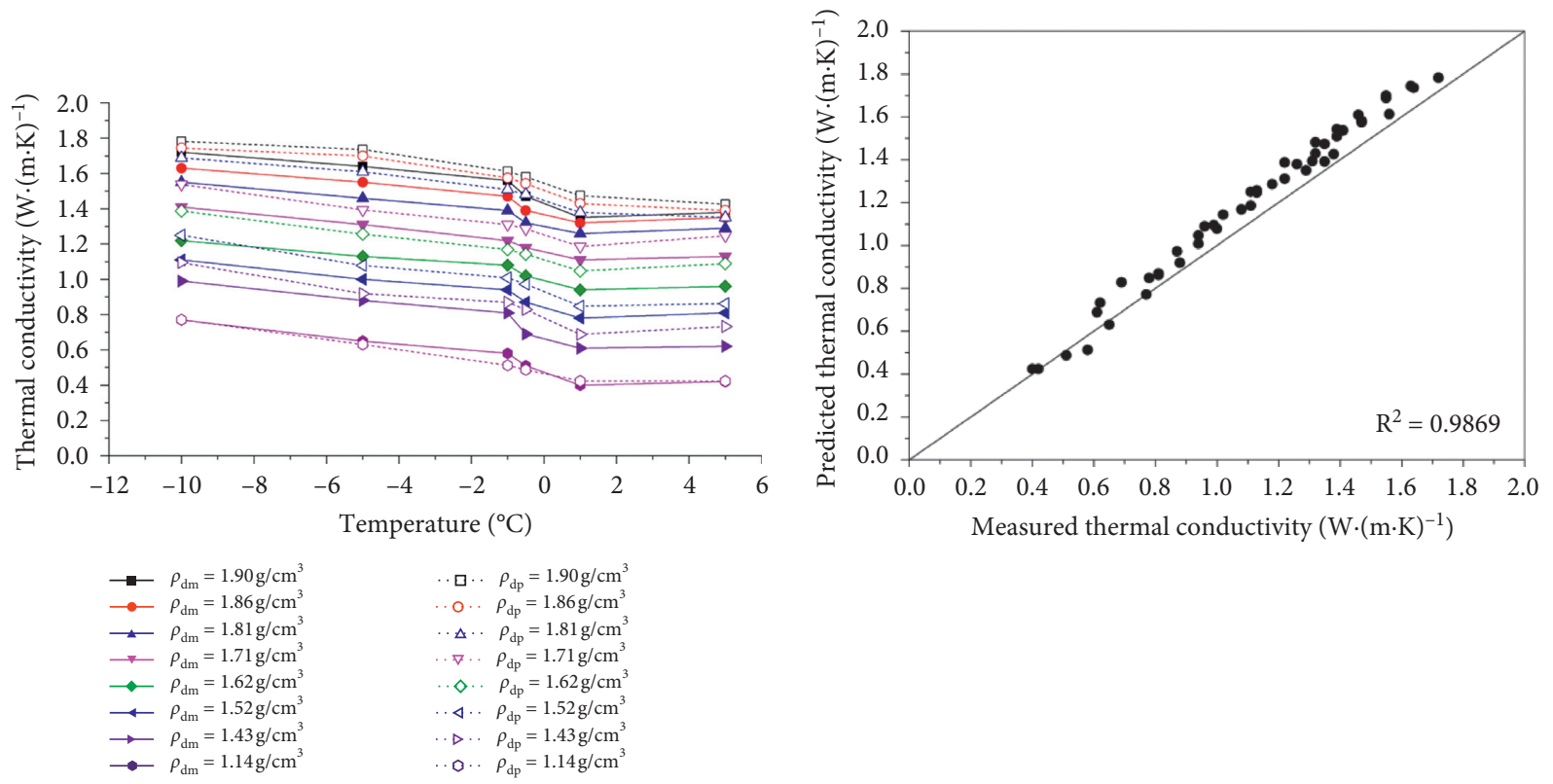

(a)

(b)

FIGURE 8: Comparison of the thermal conductivity of the soil specimens with the initial moisture content of $16 \%$ predicted by the model with the measured values. (a) Variation curve with temperature. (b) Fitting curve. 


\section{Conclusions}

This paper measures the thermal conductivity of clay under the influence of initial moisture content, initial dry density, and temperature. Then, the variation of the thermal conductivity of the soil specimens during a freezing process where the temperature changes from positive to negative is analyzed, and a predictive model is developed via the ANN technology to calculate the thermal conductivity of the soil specimens under the same experimental conditions. The main conclusions are drawn:

(1) The thermal conductivity of soils is affected by initial moisture content, initial dry density, and temperature, and the initial moisture content plays a dominant role. As the initial moisture content and initial dry density of the soil specimens increase, the thermal conductivity of the soil specimens increases

(2) During different variation stages of temperature, the variation of the thermal conductivity of the soil specimens is different. In the transition stage, the increase of the thermal conductivity is large because water transforms into ice. The variation of the thermal conductivity with temperature is related to the initial moisture content and dry density of the soil specimens. The difference between the thermal conductivity of the soil specimens at positive and negative temperatures is small when the dry density is larger than the critical dry density, while that of the soil specimens is large when the dry density is less than the critical dry density. As the negative temperature decreases, the larger the moisture content, the larger the increase of the thermal conductivity of the soil specimens

(3) The change tendency of the thermal conductivity calculated by the predictive model based on ANN is consistent with that of the laboratory-measured thermal conductivity, and both are close. Both the values of $R^{2}$ and $V A F$ of the thermal conductivity calculated by the model and the measured thermal conductivity are close to 1 , and RMSE and MAE are lower than $0.11 \mathrm{~W} /(\mathrm{m} \cdot \mathrm{K})$ and $0.1 \mathrm{~W} /(\mathrm{m} \cdot \mathrm{K})$, respectively. It indicates that the structure of the established model is reasonable, which can accurately calculate the thermal conductivity of clay.

\section{Data Availability}

The data used to support the findings of this study have not been made available because the experimental data involved in the paper are all obtained based on our designed experiments and need to be kept confidential; we are still using the data for further research.

\section{Conflicts of Interest}

The authors declare that they have no conflicts of interest.

\section{Acknowledgments}

This work was supported by the Second Tibetan Plateau Scientific Expedition and Research (STEP) program (Grant no. 2019QZKK0905), National Natural Science Funds of China (Grant nos. 41801039 and 41772325), and the Science and Technology Project of Yalong River Hydropower Development Company (Grant no. YLLHK-LHA-2019006).

\section{References}

[1] T. Ma, T. Tang, X. M. Huang, and H. Wang, "Numerical analysis on thermal regime of wide embankment in permafrost regions of Qinghai-Tibet Plateau," Journal of Central South University, vol. 23, no. 12, pp. 3346-3355, 2016.

[2] N. H. Abu-Hamdeh, A. I. Khdair, and R. C. Reeder, "A comparison of two methods used to evaluate thermal conductivity for some soils," International Journal of Heat and Mass Transfer, vol. 44, no. 5, pp. 1073-1078, 2001.

[3] B. S. Ghuman and R. Lal, "Thermal conductivity, thermal diffusivity, and thermal capacity of some Nigerian soils," Soil Science, vol. 139, no. 1, pp. 74-80, 1985.

[4] M. S. Kersten, Thermal Properties of Soils, Twin Cities, University of Minnesota Engineering Experiment Station, University of Minnesota, Minneapolis, MN, USA, 1949.

[5] S. Lu, T. Ren, Y. Gong, and R. Horton, "An improved model for predicting soil thermal conductivity from water content at room temperature," Soil Science Society of America Journal, vol. 71, no. 1, pp. 8-14, 2007.

[6] D. Barry-Macaulay, A. Bouazza, R. M. Singh, B. Wang, and P. G. Ranjith, "Thermal conductivity of soils and rocks from the Melbourne (Australia) region," Engineering Geology, vol. 164, pp. 131-138, 2013.

[7] K. M. Smits, T. Sakaki, A. Limsuwat, and T. H. Illangasekare, "Determination of the thermal conductivity of sands under varying moisture, drainage/wetting, and porosity conditionapplications in near-surface soil moisture distribution analysis," Hydrology Days, in Proceedings AGU Hydrology Days, pp. 57-65, Fort Collins, CO, USA, 2009.

[8] M. Y. Zhang, J. G. Lu, Y. M. Lai, and X. Y. Zhang, "Variation of the thermal conductivity of a silty clay during a freezingthawing process," International Journal of Heat and Mass Transfer, vol. 124, pp. 1059-1067, 2018 a.

[9] T. Zhang, C. J. Wang, S. Y. Liu, N. Zhang, and T. W. Zhang, "Assessment of soil thermal conduction using artificial neural network models," Cold Regions Science and Technology, vol. 169, Article ID 102907, 2020.

[10] D. W. Liu, D. S. Gu, T. G. Dai, and H. Herbert, "Analysis and calculation of thermal conductivity of rock in deep strata," Journal of Central South University of Technology, vol. 12, no. S1, pp. 114-119, 2005.

[11] X. T. Xu, W. D. Zhang, C. X. Fan, and G. S. Li, "Effects of temperature, dry density and water content on the thermal conductivity of Genhe silty clay," Results in Physics, vol. 16, Article ID 10283, 2020.

[12] X. Z. Xu, J. C. Wang, and L. X. Zhang, Frozen Soil Physic, Science Press, Beijing, China, 2010, in Chinese.

[13] Y. Li, M. A. Shao, W. Y. Wang, Q. J. Wang, J. F. Zhang, and J. B. Lai, "Influence of soil textures on the thermal properties," Transactions of the CASE, vol. 19, no. 4, pp. 62-65, 2003, in Chinese.

[14] H. M. Abuel-Naga, D. T. Bergado, A. Bouazza, and M. J. Pender, "Thermal conductivity of soft Bangkok clay from 
laboratory and field measurements," Engineering Geology, vol. 105, no. 3-4, pp. 211-219, 2009.

[15] L. X. Wang, Q. L. Hu, X. Z. Ling, D. S. Cai, and X. Y. Xu, “Test study on unfrozen water content and thermal parameters of Qinghai-tibet railway frozen silty clay," Journal of Harbin Institute of Technology, vol. 39, no. 10, pp. 1660-1663, 2007b, in Chinese.

[16] A. Alrtimi, M. Rouainia, and S. Haigh, "Thermal conductivity of a sandy soil," Applied Thermal Engineering, vol. 106, pp. 551-560, 2016.

[17] S. X. Chen, "Thermal conductivity of sands," Heat and Mass Transfer, vol. 44, no. 10, pp. 1241-1246, 2008.

[18] O. Nusier and N. Abu-Hamdeh, "Laboratory techniques to evaluate thermal conductivity for some soils," Heat and Mass Transfer, vol. 39, no. 2, pp. 119-123, 2003.

[19] Y. Dong, J. S. Mccartney, and N. Lu, "Critical review of thermal conductivity models for unsaturated soils," Geotechnical and Geological Engineering, vol. 33, no. 2, pp. 207-221, 2015.

[20] O. Winer, "Abhandl Math-Phys Kl KoniglSachsischenGes," vol. 32, pp. 509, 1912.

[21] D. A. Devries, "Thermal properties of soils," in Physics of the Plant Environment, W. R. Van Wijk, Ed., pp. 210-235, John Wiley \& Sons, New York, NY, USA, 1963.

[22] O. Johansen, Thermal Conductivity of Soils, Trondheim: University of Trondheim, Trondheim, Norway, 1975.

[23] J. Côté and J. M. Konrad, "A generalized thermal conductivity model for soils and construction materials," Canadian Geotechnical Journal, vol. 42, no. 2, pp. 443-458, 2005.

[24] J. Bi, M. Y. Zhang, Y. M. Lai et al., "A generalized model for calculating the thermal conductivity of freezing soils based on soil components and frost heave," Internal Journal of Heat and Mass Transfer, vol. 150, Article ID 119166, 2020.

[25] Y. Erzin, B. H. Rao, and D. N. Singh, "Artificial neural network models for predicting soil thermal resistivity," International Journal of Thermal Sciences, vol. 47, no. 10, pp. 1347-1358, 2008.

[26] F. X. He and Y. Huang, "Solution of thermal conduction coefficient from BP network," Rock and Soil Mechanics, vol. 21, no. 1, pp. 84-87, 2000, in Chinese.

[27] Y. Zhang, L. Zhou, Z. Hu et al., "Prediction of layered thermal conductivity using artificial neural network in order to have better design of ground source heat pump system," Energies, vol. 11, no. 7, p. 1896, 2018 b.

[28] N. Zhang, H. Zou, L. Zhang, A. J. Puppala, S. Liu, and G. Cai, "A unified soil thermal conductivity model based on artificial neural network," International Journal of Thermal Sciences, vol. 155, Article ID 106414, 2020.

[29] T. L. Brandon and J. K. Mitchell, "Factors influencing thermal resistivity of sands," Journal of Geotechnical Engineering, vol. 115, no. 12, pp. 1683-1698, 1989.

[30] Q. C. Fang, MATLAB R2016a Neural Network Design and Application: Analysis of 28 Cases, Tsinghua Publishing Press, Beijing, China, 2018, in Chinese.

[31] J. M. Twomey and A. E. Smith, "Validation and verification," in Artificial Neural Networks for Civil Engineers: Fundamentals and Applications, N. Kartam, I. Flood, and J. H. Garret, Eds., pp. 44-64, ASCE, New York, NY, USA, 1997.

[32] M. Banimahd, S. S. Yasrobi, and P. K. P.K. Woodward, "Artificial neural network for stress-strain behavior of sandy soils: knowledge based verification," Computers and Geotechnics, vol. 32, no. 5, pp. 377-386, 2005.

[33] K. Hornik, M. Stinchcombe, and H. White, "Multilayer feedforward networks are universal approximators," Neural Networks, vol. 2, no. 5, pp. 359-366, 1989. 